When food is available the stomachs are full and later, when zooplankton is plentiful, the mackerel feed voraciously upon this and still later, after the shoals have broken up and dispersed along the shores of the shallow coastal waters, they feed mainly on small fishes.

In 1937 a series of cruises was made in the area to the west of the mouth of the English Channel to try to obtain information concerning the spawning of the mackerel and dispersal and distribution of the young stages. Results from 1938 and 1939 are incorporated in the account. It was found that the spawning is a protracted one lasting from March until July or even August, with its maximum from mid-April to mid-May. It occurs within the area of the Continental shelf, not over great depths, but mainly well off-shore. From April until July there was a gradual eastward shifting of the locality of spawning accompanied by a diminution in the number of eggs. Later on there is found to be a similar eastward drift and decrease in numbers in the young stages. This change in locality with time is foreshadowed by the movements of the shoals which support the commercial drift fishery based on Newlyn from March to mid-June, although routine examination shows that scarcely any ripe or spent mackerel are landed on the fish market before about the end of May. It appears that fishing takes place not on the actual spawning centres but on the inner (landward) edges of them where the fish that have not yet spawned are located. The spawning period of the individuals is found to be a protracted one. The first indication of the spawning condition is the presence of ripe eggs which appear on the outside of the ovary, widely scattered among unripe eggs. Later these ripe eggs pass into the lumen of the ovary, which, externally, then reverts to an unripe appearance. The ripe eggs are shed and the process recurs, possibly many times, before the ovary is fully spent. For study of age and growth-rate it was found that the otoliths carefully prepared are of more value than the scales. Consequently this otolith method has been adopted. Preliminary work shows as yet no dominating year class. Examination of skeletons for racial characters, not yet fully worked out, indicates that the only variant that can be foundthe numbers of the thoracic vertebræ with 'open' hæmal arches-shows some variation from sample to sample.

J. Furnestin in Appendix III shows results chiefly on hydrography and plankton from the entrance to the Channel and waters south of the Irish Sea, and G. P. Farran in Appendix IV deals mainly with the plankton as food for the mackerel.

Besides these researches on the mackerel there are reports by J. le Gall and J. Furnestin on the sardine, plaice, and sand eel, by Fen Hsüeh on Manx herring shoals, by P. Desbrosses on the John Dory and G.P. Farran on surface temperature observations at Coningbeg Lightship on the south coast of Ireland.

\title{
AUTOMATIC SERVICE OF LONG-DISTANCE TELEPHONE CALLS
}

$F^{2}$ ULL automatic service for toll or long-distance telephone connexions, as they are variously termed, has been in operation in a number of European countries for some years. The administrations and operating companies of countries which have not yet adopted this service are anxiously considering methods of improving their service and reducing its cost. An important paper by W. Hatton, the technical administrator of the Bell Telephone Manufacturing Company at Antwerp, is published in the January issue of Electrical Communication, a quarterly journal issued by the International Standard Electric Corporation of New York, U.S.A.

When converting telephone networks of national dimensions from manual to automatic operation, certain problems arise which can be dealt with in a purely technical manner, while others cannot be solved without due regard to the reaction of the telephone subscriber. Signalling over long-distance circuits by voice-frequency currents, automatic regulation of the transmission level and other technical features of long-distance service do not directly concern the subscriber, provided that the final result is satisfactory. The manner in which charges for long-distance service are established and the form in which the monthly or quarterly account is presented are matters which have both technical and administrative aspects, and in which the subscriber is keenly interested.

To operate long-distance service on an automatic basis, calls must be charged automatically, and the method adopted for this must give complete satis- faction to the subscriber. Prior to the introduction of a system of automatic ticketing, first applied in Belgium, there appeared to be no method of charging subscribers automatically for their long-distance connexions, except by means of the message register. This 'message' method, known to the telephone world as 'time or zone' or sometimes as 'multiple metering', has its disadvantages. A summary of these disadvantages shows that some of them are serious and that business organizations would be reluctant to accept a monthly or quarterly bill without particulars of the individual charges for each of their long-distance connexions. In the case of hotels, these particulars would in most cases need to be furnished immediately on demand. The real solution would have to be one which maintains the present situation between the charges for local and long-distance tariffs (allowing each to be developed to suit their separate requirements) and which at the same time provides a record giving the date, the time of day, the duration of call and the cost of the message, preferably printed on a ticket.

From the practical point of view the design of such a system of automatic ticketing must permit of its introduction to existing exchanges with the minimum of modification to the equipment already installed and in operation. The author gives a sketch of such a system in operation in Belgium which seems to be in every way satisfactory. Although this system is quite a recent invention, there are already installed or on order 150,000 lines.

An excellent description is given by $\mathrm{Mr}$. Hatton of 
the problems that had to be faced in designing an automatic ticketing system in three areas in Belgium, namely, Brussels, Antwerp and Malines. The urban network of Brussels contains fifteen exchanges of the rotary type, some dating back to 1922. The normal capacity is 115,000 lines, and this network furnishes a good example of the manner in which automatic ticketing can be added to existing equipments. The author states that Antwerp, Liége, Charleroi and other Belgian towns will follow the method adopted for Brussels.

The first installation of automatic ticketing was put into service in Bruges in 1936, and was rapidly followed by installations in Ostend and twelve other towns in Belgium. During the period July 1-September 15,1937 , a check of 62,000 ticketed calls revealed 80 tickets, or $0 \cdot 13$ per cent, bearing incomplete or incorrect details, and these results go far to prove that full-automatic methods can be applied to long-distance service with the same success as to local service.
The tickets provide the traffic department with valuable information, and also give a remarkably clear picture of the operating efficiency of the exchange. Each long-distance call is recorded whether it be an effective connexion or whether it results in "busy", "no answer", "wrong number", or "premature release". Equipment faults which might otherwise remain unsuspected and undetected are brought to light by the indisputable evidence of the ticket. Naturally, further developments in this field are to be anticipated. It may prove advantageous to use a small number of high-speed printers which are engaged only at the termination of a call.

A form of ticket may be produced which can be automatically sorted, and, ultimately, doubtless mechanized-accounting will further dispense with the need for human intervention. Finally, it is anticipated that automatic ticketing will prove immensely valuable in Europe when the development of international long-distance service on a fully automatic basis becomes possible.

\section{ANALYSIS OF FIELD TRIALS}

$\mathrm{V}^{\mathrm{A}}$ ARIETY testing forms an essential part of the work of the plant breeder and so he needs an adequate technique for the design and statistical analysis of field trials. His requirements in this direction are, however, rather specialized, the prime necessity being a method of comparing a large number of selected lines, though the careful testing of a small number of valuable new strains against standard varieties is also of importance.

Now one of the greatest advances made by modern statistics has been to revolutionize field trial technique. Until recently, however, the development of field designs was largely concerned with manurial and other such trials, where a limited number of treatments are applied and where interactions of these treatments are detectable and potentially of interest. Furthermore, when it was shown that multiple interactions are seldom if ever significant, a new technique, that of confounding, became possible. A design involving confounding purposely sacrifices information on less important interactions, in order to make the main comparisons with more precision.

Clearly all field trials must be based on the same principles as these 'treatment' designs; but the latter in themselves are not fully suited to the plant breeder's work. He often requires to work with large numbers of varieties and has no uninteresting 'interaction' comparisons which may be sacrificed by simple confounding. His requirements have, however, recently received special attention, and appropriate lay-outs have been developed. For example, the quasi-factorial designs, involving a somewhat complicated application of confounding, meet the needs of the plant breeder admirably but are in general of small value to those interested in soil treatment.

Thus it is very appropriate that the Imperial Bureau of Plant Breeding and Genetics should publish a technical communication on the subject of field trials, by an author who has been associated for many years with this branch of statistical work*. The publication is essentially introductory in scope, and the contents have been admirably chosen to fulfil this purpose. The first sections deal with the general principles of yield determination and the measurement of experimental error. Then follow descriptions of the randomized block and Latin square designs, together with details of their numerical analysis. The discussion of the use of the Latin square well illustrates the considerations involved in the choice of a design appropriate to an experiment. Multiple factor experiments are next dealt with and the principles of orthogonality and confounding introduced by a simple example. Finally, the split plot technique, which is especially suited to combined variety and manurial trials, and the quasi-factorial designs are briefly considered. The latter is somewhat complex for introduction into an elementary account, but its inclusion is amply justified by its pre-eminent position among layouts for testing a large number of varieties.

The presentation of the material is adequate, though more open to criticism than is the choice of contents, in that it tends at times to be too technical. For example, the introduction of the terms 'selfconjugate' and 'transformation set' into the section on Latin squares is unnecessary as their meanings are not explained, the reader being referred elsewhere for an account of their use. Thus they do not materially aid the argument and are somewhat terrifying to the beginner. The discussion of the $t$ test in the third section could also be made much more real for the biologist by the use of actual experimental data as illustrative matter, rather than the very artificial example of two varieties with unequal means but exactly equal variances, which is in fact used.

There can, however, be no doubt that plant breeders will find this publication a helpful introduction to the subject of field trials. Nor will its use end there, as the list of more advanced works given, together with short notes on their contents, in the last section, will serve as a guide for later reading and reference.

K. Mather.

- Field Trials: Their Lay-out and Statistical Analysis. By John Wishart. (Imperial Bureau of Plant Breeding and Genetics, Cambridge.) 